\title{
Erratum to: High-speed mixture fraction and temperature imaging of pulsed, turbulent fuel jets auto-igniting in high-temperature, vitiated co-flows
}

\author{
Michael J. Papageorge ${ }^{1} \cdot$ Christoph Arndt $^{2} \cdot$ Frederik Fuest $^{1} \cdot$ Wolfgang Meier $^{2}$. \\ Jeffrey A. Sutton ${ }^{1}$
}

Published online: 28 December 2015

(C) Springer-Verlag Berlin Heidelberg 2015

\section{Erratum to: Exp Fluids (2014) 55:1763 DOI 10.1007/s00348-014-1763-z}

In the original publication the experimental approach to simultaneously measure quantitative time-resolved image sequences of mixture fraction and temperature during pulsed fuel injection into a high-temperature, vitiated, oxidizer stream is presented. The methodology and scalar results (mixture fraction and temperature) as presented are correct, but unfortunately the fuel tube diameter of $2 \mathrm{~mm}$ for the DLR jet-in-hot-co-flow (JHC) is incorrect, which leads to errors in the presentation of results in the original publication. The correct fuel tube diameter is $1.5 \mathrm{~mm}$, which changes the reported operating conditions and normalized spatial locations of the measurements. Many measurement locations (axial and radial) reported were normalized by the tube diameter $(d)$. While the normalized spatial positions are incorrect, the absolute spatial positions are correct. In this erratum, the correct operating conditions are presented along with corrected figures and figure captions using absolute spatial position to avoid confusion. When referring to the original publication, any reported normalized spatial position $(x / d$ or $r / d)$ in the text should be multiplied by 2 to yield the correct spatial position in units of millimeters.

\section{Presentation of results}

Table 1 in the original publication contains operating conditions for five experimental test cases. The operating conditions (accounting for the correct fuel tube diameter) should have been presented as shown below (Table 1).

The presentation of Figs. 3b, 6, 10, 11, 13, 14, 15, 16, 17,18 , and 19 is incorrect in the original publication. The correct figure presentation and figure captions are presented here (Figs. 3b, 6, 10, 11, 13, 14, 15, 16, 17, 18, 19).

The online version of the original article can be found under doi:10.1007/s00348-014-1763-z.

Jeffrey A. Sutton

sutton.235@osu.edu

1 Department of Mechanical and Aerospace Engineering, Ohio State University, Columbus, OH, USA

2 Institute of Combustion Technology, German Aerospace Center (DLR), Stuttgart, Germany 
Table 1 Operating conditions

\begin{tabular}{|c|c|c|c|c|c|c|c|c|c|c|}
\hline \multicolumn{4}{|l|}{ Jet } & \multicolumn{7}{|c|}{ Co-flow } \\
\hline Fuel & $U(\mathrm{~m} / \mathrm{s})$ & $R e$ & $\xi_{\mathrm{s}}$ & $\phi$ & $\dot{M}(\mathrm{~kg} / \mathrm{s})$ & $T_{\mathrm{ox}}(\mathrm{K})$ & $T_{\text {ad }}(\mathrm{K})^{\mathrm{a}}$ & $X_{\mathrm{N}_{2}}^{\mathrm{b}}$ & $X_{\mathrm{O}_{2}}^{\mathrm{b}}$ & $X_{\mathrm{H}_{2} \mathrm{O}}^{\mathrm{b}}$ \\
\hline $\mathrm{CH}_{4}$ & 177 & 15,400 & 0.029 & 0.465 & $4.8 \times 10^{-3}$ & 1490 & 1563 & 0.719 & 0.102 & 0.178 \\
\hline $\mathrm{CH}_{4}$ & 177 & 15,400 & 0.028 & 0.485 & $4.7 \times 10^{-3}$ & 1520 & 1603 & 0.716 & 0.097 & 0.185 \\
\hline $\mathrm{CH}_{4}$ & 177 & 15,400 & 0.027 & 0.506 & $4.5 \times 10^{-3}$ & 1540 & 1646 & 0.714 & 0.093 & 0.192 \\
\hline DME & 144 & 44,510 & 0.064 & 0.380 & $5.6 \times 10^{-3}$ & 1330 & 1372 & 0.731 & 0.120 & 0.148 \\
\hline $\mathrm{C}_{3} \mathrm{H}_{8}$ & 129 & 39,590 & 0.040 & 0.360 & $5.8 \times 10^{-3}$ & 1274 & 1326 & 0.730 & 0.128 & 0.141 \\
\hline
\end{tabular}

a Calculated with a reactant temperature of $290 \mathrm{~K}$

b Determined during data processing as described in Sect. 3.2
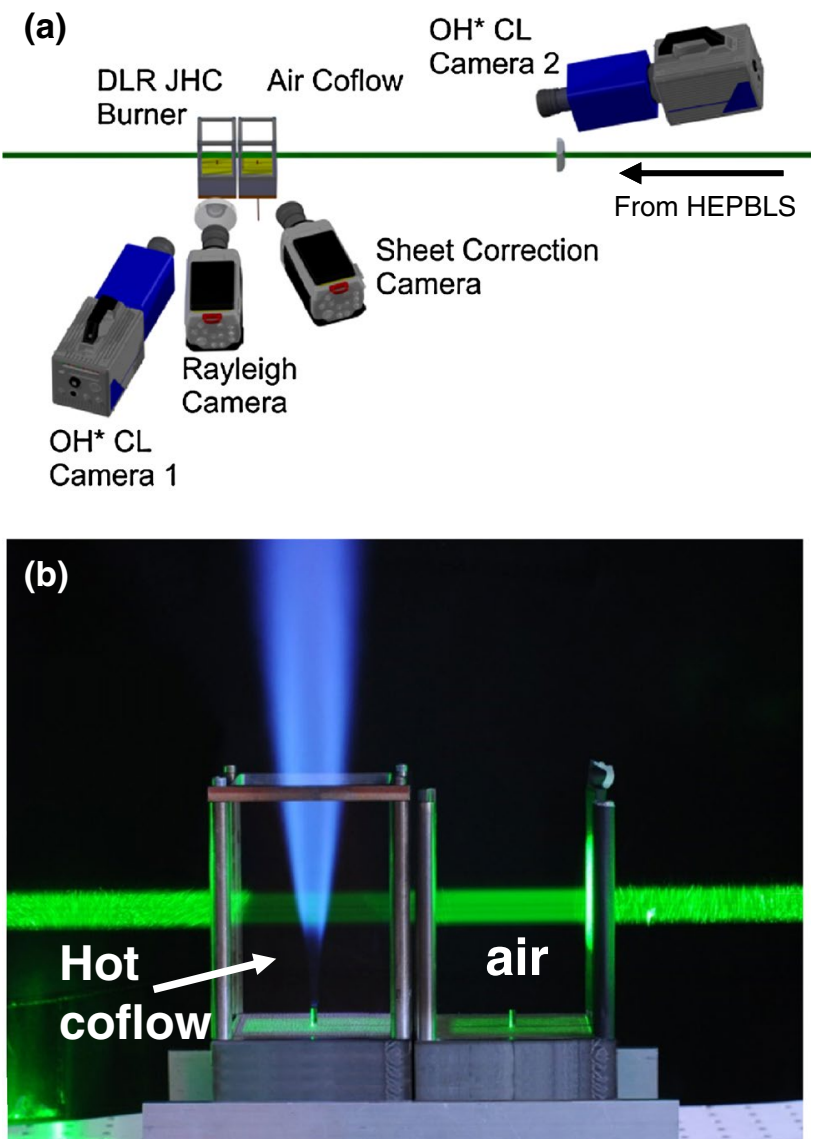

Fig. 3 a Schematic of the high-speed imaging setup used for the auto-ignition experiments. b Photograph of a $R e=44,510 \mathrm{DME}$ flame (1330 K oxidizer) under steady operating conditions
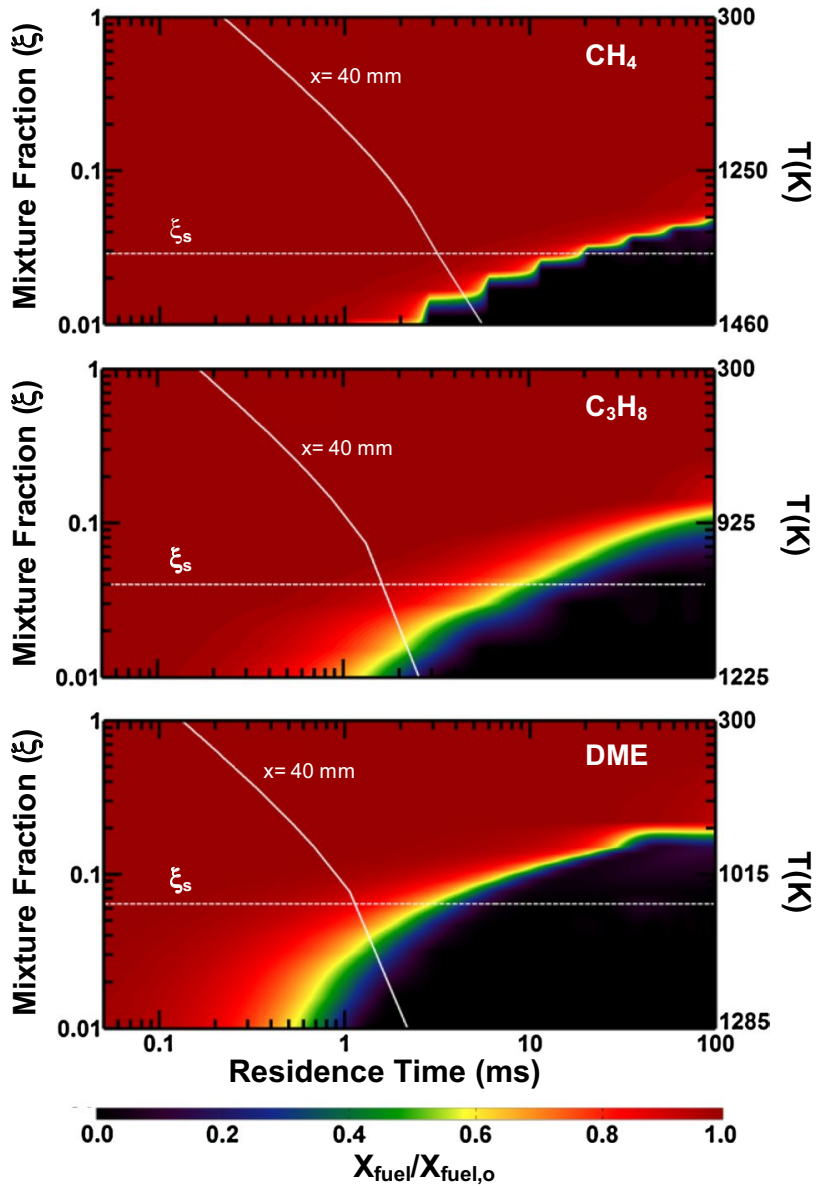

Fig. 6 Results from a series of plug flow reactor (PFR) simulations showing the normalized fuel mole fraction $\left(X_{\text {fuel }} / X_{\text {fuel,o }}\right)$ as a function of mixture fraction/temperature and PFR residence time $\left(\tau_{\mathrm{R}}\right)$. A value of $X_{\text {fuel }} / X_{\text {fuel,o }}=1$ indicates that no reaction of the fuel has taken place at a given time, $\tau_{\mathrm{R}}$. The white solid contour is an estimated maximum residence time for the cold jet-in-hot-co-flow conditions at an axial position of $x=40 \mathrm{~mm}$. The white dotted line represents the stoichiometric mixture fraction, $\xi_{\mathrm{s}}$, value 

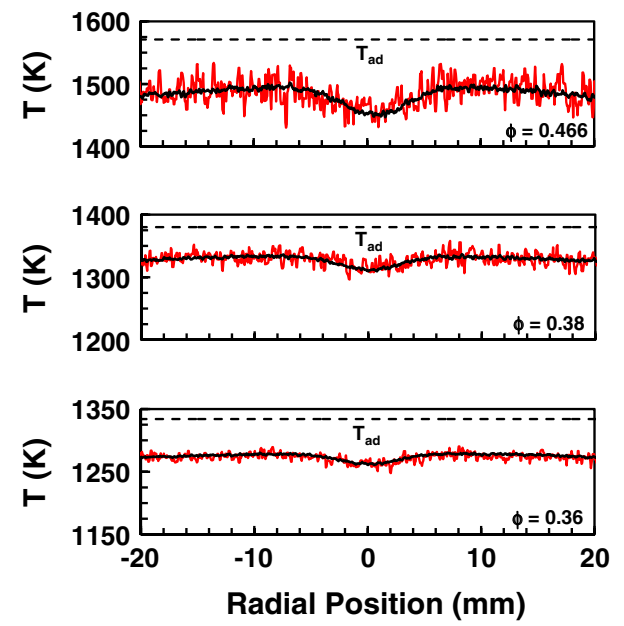

Fig. 10 Radial profiles of the oxidizer temperature (no jet flow) at an axial position of $40 \mathrm{~mm}$ downstream of the fuel tube exit for three experimental cases shown in Table 1. The red line represents an instantaneous profile, and the black line represents the average from 100 profiles. The dashed line represents the adiabatic flame temperature, $T_{\text {ad }}$, and is shown for reference

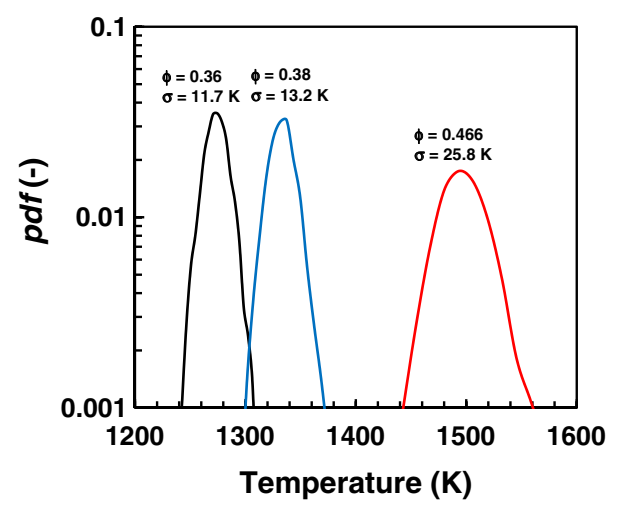

Fig. 11 Probability density functions (pdf) of the measured oxidizer temperature for three experimental cases shown in Table 1 . The pdf was constructed from a single, instantaneous image representing 15,000 data points from radial positions spanning $12-18 \mathrm{~mm}$ from centerline at axial locations spanning 34-46 mm downstream of the fuel tube exit. The standard deviation derived from each pdf is listed above the corresponding distribution

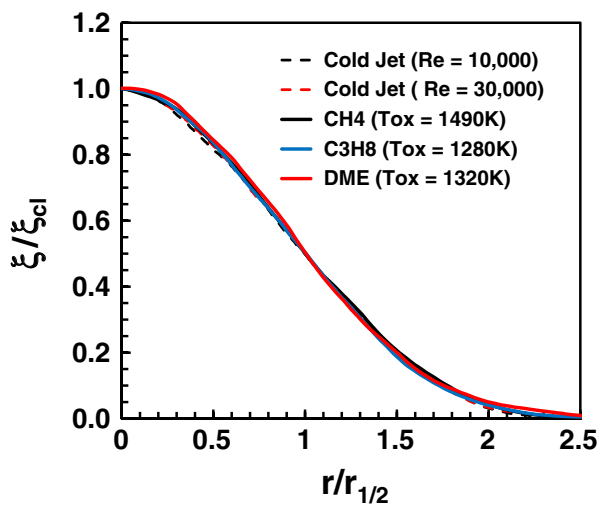

Fig. 13 Normalized mixture fraction $\left(\xi / \xi_{\mathrm{cl}}\right)$ profiles as a function of normalized radial position $\left(r / r_{1 / 2}\right)$. The dashed lines correspond to $T=300 \mathrm{~K}$, non-reacting propane jets issuing into air measured $160 \mathrm{~mm}$ downstream of an 8-mm tube. The solid lines correspond to the fuel jets in hot, vitiated co-flows as identified in Table 1, measured $40 \mathrm{~mm}$ downstream of the exit of the current 1.5 -mm tube. Note all curves exhibit self-similarity and collapse upon one another 
Fig. 14 Example 10-kHz image sequence of the transient fuel injection of $\mathrm{C}_{3} \mathrm{H}_{8}$ into a $T=1270 \mathrm{~K}$ co-flow at an axial position of $40 \mathrm{~mm}$ downstream of the fuel tube exit. The steadystate Reynolds number of the jet is 39,590
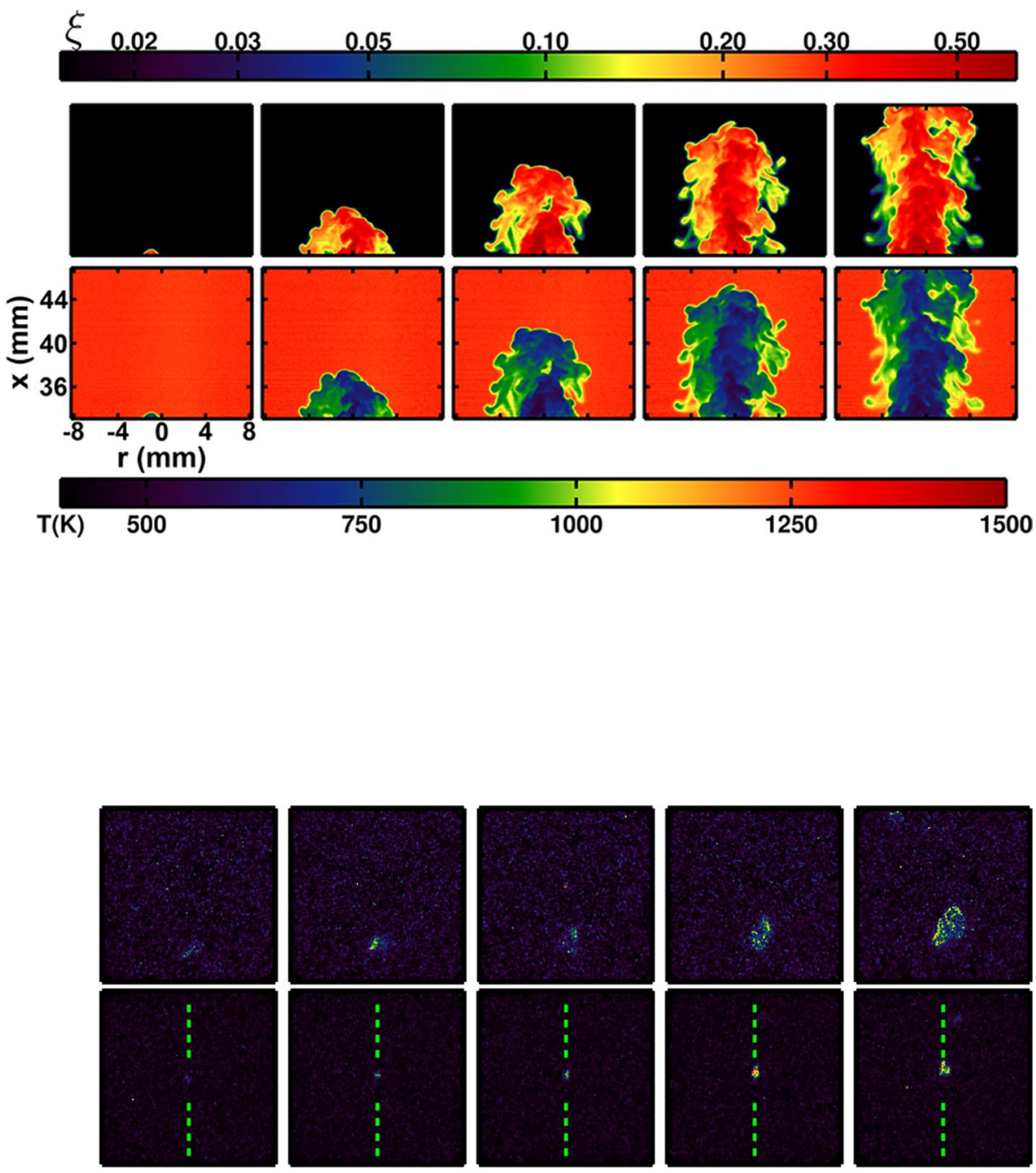

planar Rayleigh scattering. Initial kernel forms outside of the laser sheet
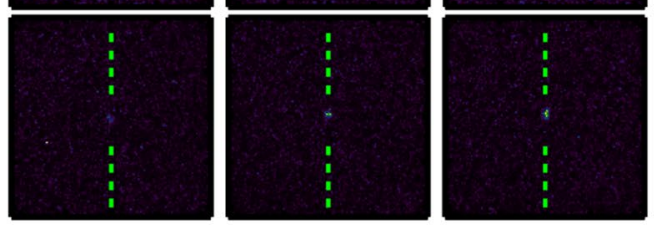

(a)

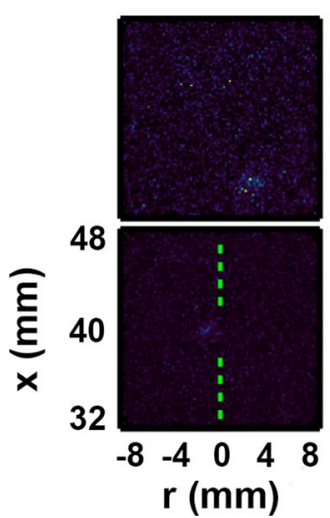

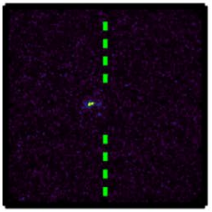

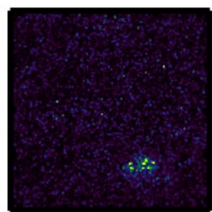

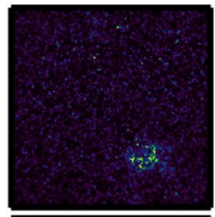
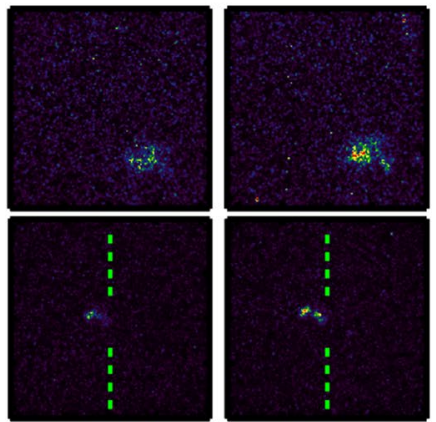

(b)
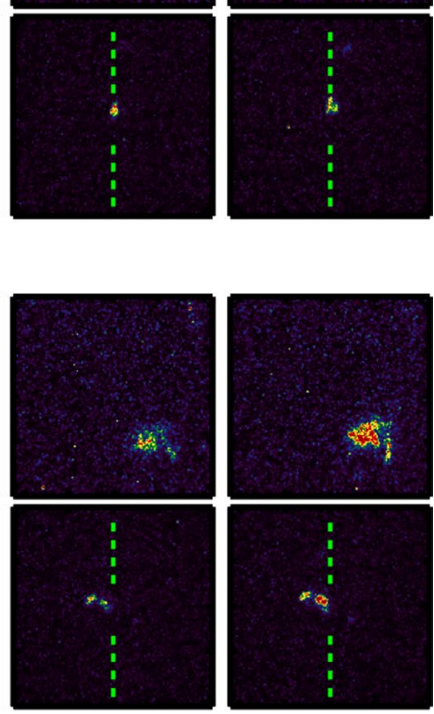
Fig. 16 Example 10-kHz image sequences of mixture fraction (top), $\mathrm{OH}^{*} \mathrm{CL}$ (middle), and temperature (bottom) for the case of $\mathrm{C}_{3} \mathrm{H}_{8}$ auto-igniting in a $T=1270 \mathrm{~K}$ co-flow. The circled regions correspond to the spatial location of the initial ignition kernel formation and subsequent displacement

Fig. 17 Example 10-kHz image sequences of mixture fraction (top), $\mathrm{OH}^{*} \mathrm{CL}$ (middle), and temperature (bottom) for the case of $\mathrm{CH}_{4}$ auto-igniting in a $T=1490 \mathrm{~K}$ co-flow. The circled regions correspond to the spatial location of the initial ignition kernel formation and subsequent displacement
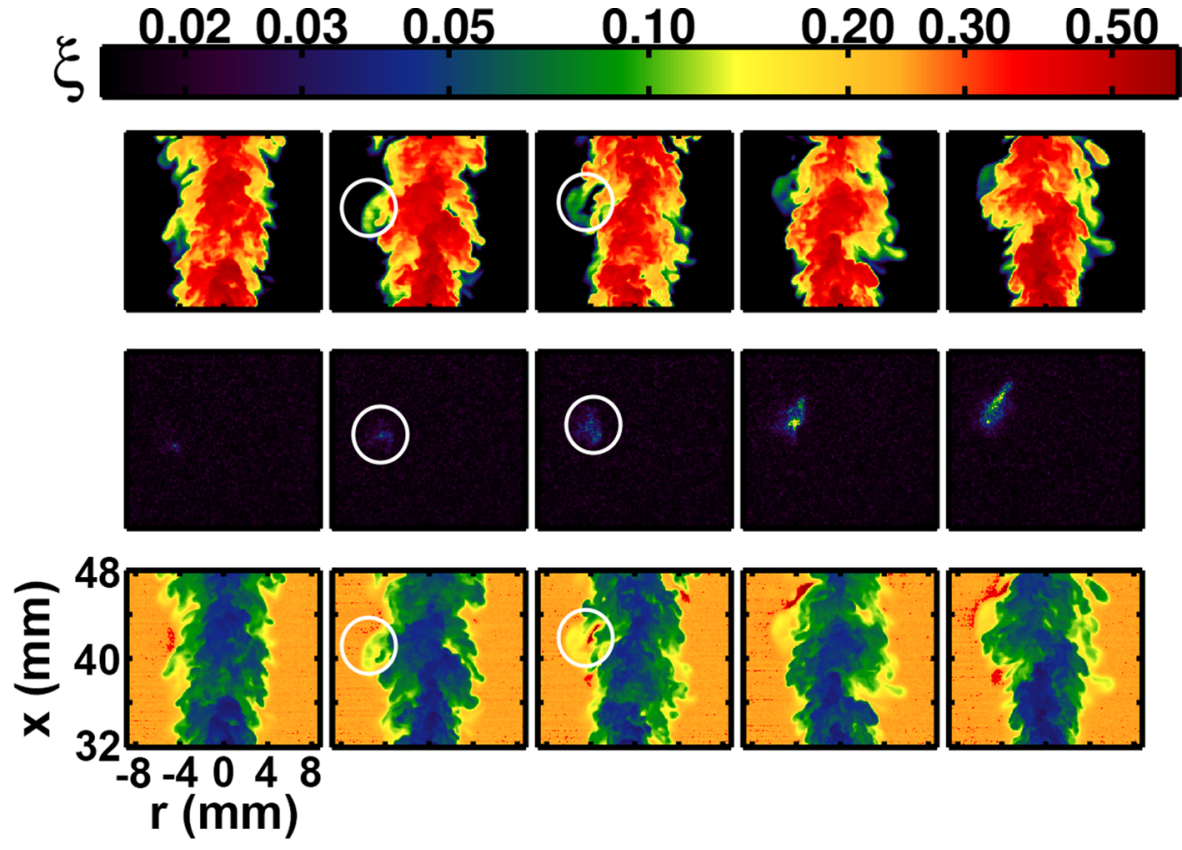

$T(K)$
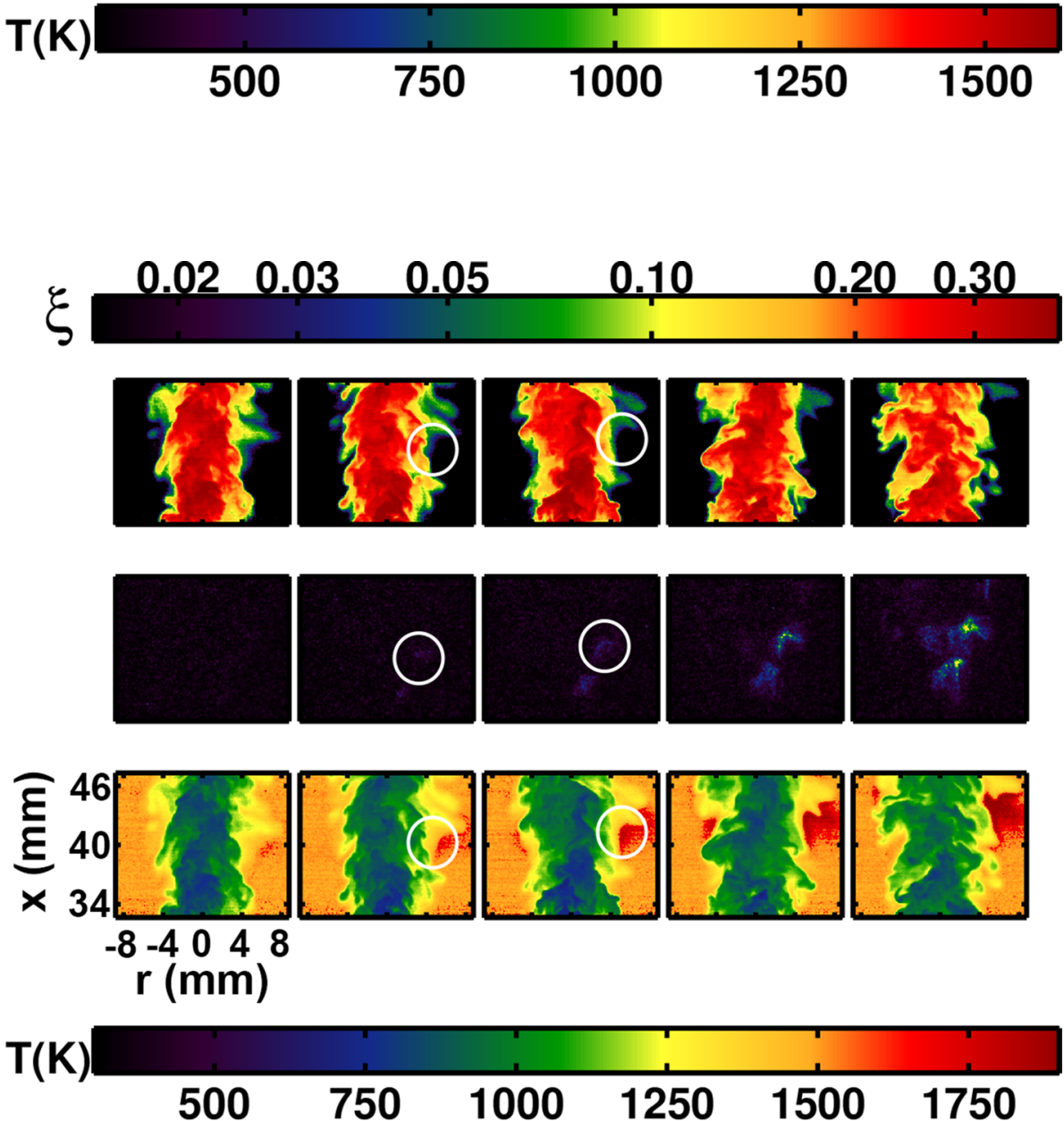
Fig. 18 Example ten-frame, $10-\mathrm{kHz}$ image sequence of $\mathrm{OH}^{*} \mathrm{CL}($ top $)$ and temperature (bottom) for the case of DME auto-igniting in a $T=1330 \mathrm{~K}$ co-flow. The circled regions correspond to the spatial location of the initial ignition kernel

formation and subsequent

displacement
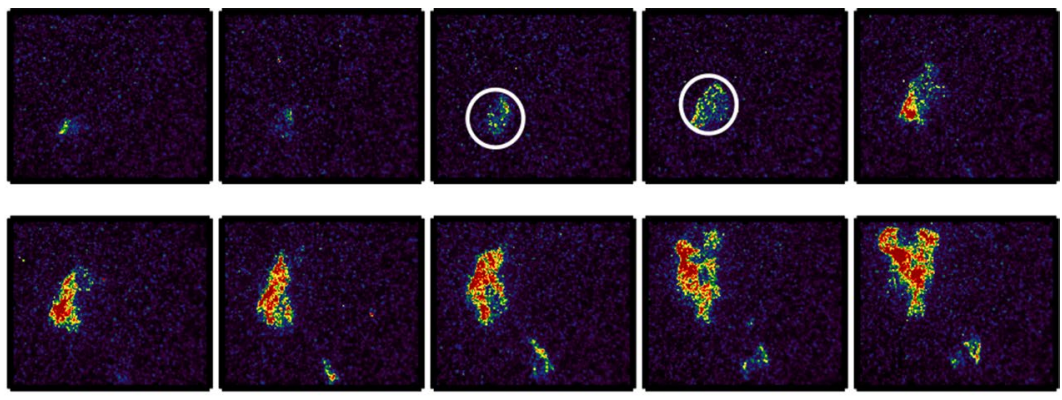

(a)
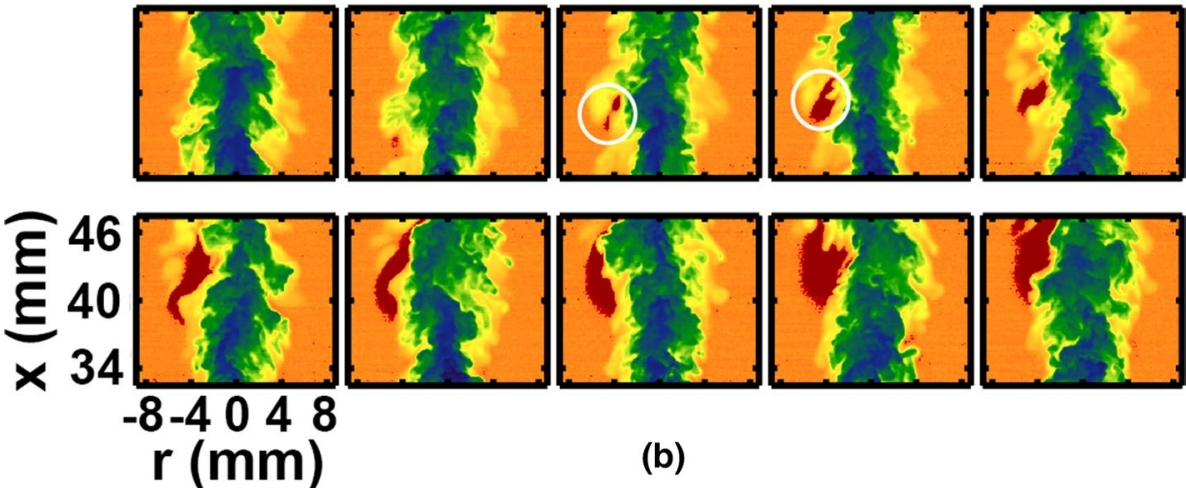

(b)
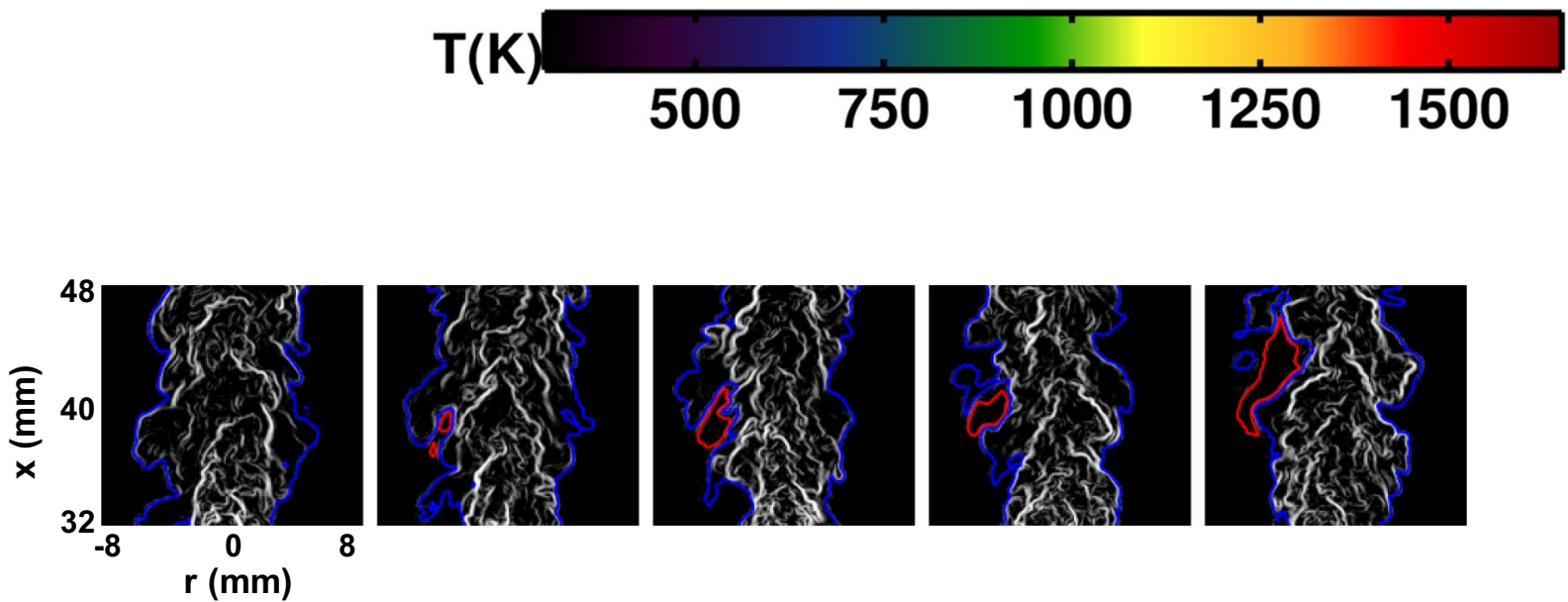

Fig. 19 Example image sequence of the logarithm of the scalar dissipation rate for the case of DME auto-igniting in a $T=1330 \mathrm{~K}$ coflow. The five images correspond to frames $2-6$ of Fig. 18. Overlaid on the scalar dissipation rate layers are the stoichiometric mixture

fraction contour $\left(\xi_{\mathrm{s}}\right.$, shown as blue solid line $)$ and a $T=1380 \mathrm{~K}$ isocontour (red line) denoting the onset and initial displacement of the auto-ignition kernel 